\title{
Constructing Canals on Mars: Event Astronomy and the Transmission of International Telegraphic News
}

Joshua Nall, University of Cambridge

\begin{abstract}
This essay presents a new explanation for the emergence after 1877 of public and expert fascination with a single observed feature of the planet Mars: its network of "canals." Both the nature of these canals and their widespread notoriety emerged, it is argued, from a novel partnership between two practices then in their ascendancy: astrophysics and the global telegraphic distribution of news. New technologies of global media are shown to have become fundamentally embedded within the working practices of remote astrophysical sites, entangling professional spaces of observation with popular forms of journalism. These collaborations gave rise to a new type of "event astronomy," as exemplified by the close working relationship forged between the enterprising Harvard astronomer William Henry Pickering and the New York Herald. Pickering's telegrams to the Herald, sent from his remote mountain outstation in Arequipa, Peru, are shown to be at the heart of the "great Mars boom" of August 1892, with significant consequences for emerging and contested accounts of the red planet. By tracing the particular transmission effects typical to this new kind of astronomical work, the essay shows how the material, temporal, and linguistic constraints imposed by telegraphic news distribution shaped and bounded what could be said about, and therefore what could be known about, Mars.
\end{abstract}

A lady of the inanely inquisitive kind having met an eminent astronomer, implored permission to ask him one question. "Certainly, madam," he replied,

Joshua Nall is Curator of Modern Sciences at the Whipple Museum of the History of Science, in the Department of History and Philosophy of Science at the University of Cambridge. His research focuses on mass media and the material culture of the physical sciences after 1800, especially early astrophysics and astrobiology. Department of History and Philosophy of Science, University of Cambridge, Cambridge CB2 3RH, United Kingdom; jfkn2@cam.ac.uk.

Acknowledgments. Work for this essay was assisted by a five-month research fellowship in the John W. Kluge Center of the Library of Congress, funded by the U.K. Arts and Humanities Research Council. I thank all the staff and scholars at the Kluge Center who contributed to this fruitful trip. I am grateful to the librarians and archivists at the Library of Congress, especially Tom Mann, and to Harvard University Archives for their assistance and for granting permission to quote and reproduce images of their materials. For their insightful commentary on drafts of this essay I thank Helen Curry, David DeVorkin, Alexandra Ion, Bernard Lightman, Simon Schaffer, Jim Secord, and three anonymous referees for Isis.

Isis, volume 108, number 2. (C) 2017 by The History of Science Society.

All rights reserved. 0021-1753/2017/0108-0003\$10.00.

280 
"if it isn't about Mars." It was about Mars. That was the time of the great Mars boom, when public imbecility and journalistic enterprise combined to flood the papers and society with "news from Mars," and queries concerning Mars, most exasperating to grave thinkers and hard workers in science. The occasion of the excitement was this. On August 4, 1892, Mars stood right opposite to the sun, at a distance from the earth of less than 35,000,000 miles. -Agnes Mary Clerke (1896)

$\mathrm{F}$ our years after the event, Agnes Mary Clerke looked back on the "great Mars boom" of 1892 with a mixture of annoyance and curiosity. As she knew well, the events of that year had launched the era's most controversial and public astronomical debate, over whether visual and spectroscopic evidence indicated the presence of life-possibly even intelligent life-on Earth's outer neighbor. Water had been detected on the planet, seasonal changes to its appearance had been linked to a vibrant Earth-like climate, and a network of curiously geometric straight lines, dubbed "canals," had been sighted and resighted. Writing for the Edinburgh Review, Clerke assessed the latest slew of works to appear on these subjects, taking the opportunity to look back at the episode's origin event and expose what she saw as its unfortunate consequences. ${ }^{1}$ As the era's most widely respected historian and analyst of astronomical work, Clerke spoke explicitly for the discipline's establishment base, its "grave thinkers and hard workers," many of whom doubted the more sensational conclusions that had been drawn during and immediately following the drama of August 1892. Crucially, Clerke's critique linked the exasperation of her astronomical colleagues to their work's entanglement with outside agents, above all an inquisitive but slow-witted public and the unscrupulous journalists who stoked and manipulated that public's interest. For its participants, then, the "great Mars boom" was an astronomical event inextricably bound up with issues of communication and reception. Public fascination with the possibility that Mars might be inhabited was a component of, rather than a secondary consequence from, astronomical work on the planet.

Accounts of this kind of entanglement of scientific practice and the public sphere are now commonplace in our discipline. The problem of how specific, situated, locally produced knowledge travels and becomes apparently global is a central concern of much recent work in science studies. This focus on science as communication forces us to take seriously the material, temporal, and spatial dimensions of the texts, images, and objects that constitute the doing of science. A long-standing concern with "science as practice" has, as a result, been augmented in recent years by an understanding of knowledge-making as a form of communicative action. These works are, by and large, accounts of authorship and reception. They take authorial voice, publication genre, market forces, and reader response as integral points of analysis within accounts of the scientific world. Their focus, therefore, is usually on books and journals, and the trajectory they trace is typically very clear, from the individualized sites of knowledge production out into the marketplace of the sciences' various publics. ${ }^{2}$

\footnotetext{
${ }^{1}$ [Agnes Mary Clerke], “New Views about Mars," Edinburgh Review, 1896, 184:368-385 (attributed to Clerke by the Wellesley Index). A good overview of the debates on Mars is given in William Sheehan, The Planet Mars: A History of Observation and Discovery (Tucson: Univ. Arizona Press, 1996), pp. 58-97; and Michael J. Crowe, The Extraterrestrial Life Debate, 1750-1900: The Idea of a Plurality of Worlds from Kant to Lowell (Cambridge: Cambridge Univ. Press, 1986), pp. 480-546.

${ }^{2}$ James A. Secord, "Knowledge in Transit," Isis, 2004, 95:654-672. Highlights among a now vast literature include Jonathan R. Topham, "Science and Popular Education in the 1830s: The Role of the Bridgewater Treatises," British Journal for the History of Science, 1992, 25:397-430; Iwan Rhys Morus, "Manufacturing Nature: Science, Technology, and Victorian Consumer Culture," ibid., 1996, 29:403-434; Secord, Victorian Sensation: The Extraordinary Publication, Reception, and Secret Authorship of
} 
This essay is an attempt to augment such trajectories by shifting our focus away from reception and toward transmission. I want to show how public forms of discourse were embedded within the astronomical work that made the "great Mars boom." This means turning our attention toward the material movement of information during the processes that constitute scientific work itself. A central focus here, therefore, is the material dimensions of transmission technologies, considered in terms of both specific material tools (e.g., the telegraph) and more general media genres (e.g., the newspaper). Such technologies, designed to enable knowledge to travel, also impose specific limits on how that knowledge can travel, shaping and bounding the movement of information. They define the scale, both spatial and temporal, on which the sciences are able to work. Their use is neither neutral nor passive, requiring considered choices on the part of the actors who seek to deploy them and constant work to make those choices count. And despite this work, communication technologies almost always produce effects that exceed or undermine the intended functions that those actors hoped they would serve. ${ }^{3}$ These are practical problems that impinge upon, and thus in part construct, scientific work itself. More than mere conduits, communication technologies are embedded within the working worlds of the sciences - multiplying, stabilizing, and therefore co-constituting the knowledge these worlds produce. ${ }^{4}$ This means that as well as thinking of knowledge in transit as a matter of authors and audiences, we also need to think of it as a practical entanglement of scientific praxis and material transmission technologies. By pushing our focus back into the laboratory or observatory and then out from there via material means-wires, submarine cables, newsprint - we can observe the effects that these technologies have on shaping, and therefore making, knowledge.

This reorientation is particularly important for understanding the "great Mars boom." Because, as Clerke's commentary makes clear, this episode is so clearly bound up with public consumption and engagement, it is all too easy to consider it almost exclusively at the level of a "popular" scientific phenomenon - what we might call a "second-order" event, separate from and temporally subsequent to astronomical work itself. At worst, this approach has produced accounts that depict fin-de-siècle debates over the possibility of intelligent life on Mars as nothing more than "a clash of amateurs versus professionals," in which the "imagination and fancy" of the former can be directly contrasted with the "intellectual sobriety and rigor" of the latter. ${ }^{5}$ Recent cultural histories of Mars have done much to correct this simple bifurcation,

\footnotetext{
"Vestiges of the Natural History of Creation" (Chicago: Univ. Chicago Press, 2000); James Mussell, Science, Time, and Space in the Late Nineteenth-Century Periodical Press (Aldershot: Ashgate, 2007); Bernard Lightman, Victorian Popularizers of Science: Designing Nature for New Audiences (Chicago: Univ. Chicago Press, 2007); Aileen Fyfe and Lightman, eds., Science in the Marketplace: Nineteenth-Century Sites and Experiences (Chicago: Univ. Chicago Press, 2007); Ralph O'Connor, The Earth on Show: Fossils and the Poetics of Popular Science, 1802-1856 (Chicago: Univ. Chicago Press, 2008); the various publications of the SciPer project, http://www.leeds.ac.uk/arts/info/125183/sciper_project/2203/publications; and the Focus section "Historicizing 'Popular Science,'” Isis, 2009, 100:310-368.

${ }_{3}^{3}$ James Carey, Communication as Culture: Essays on Media and Society (New York: Routledge, 2009), pp. 155-177; Mary Poovey, "The Limits of the Universal Knowledge Project: British India and the East Indiamen," Critical Inquiry, 2004, 31:183202; Bruce Lewenstein, "From Fax to Facts: Communication in the Cold Fusion Saga," Social Studies of Science, 1995, 25:403436; Jacques Derrida, “Archive Fever: A Freudian Impression," Diacritics, 1995, 25:9-63, esp. pp. 17-18; Timothy Lenoir, ed., Inscribing Science: Scientific Texts and the Materiality of Communication (Stanford, Calif.: Stanford Univ. Press, 1998); Mussell, Science, Time, and Space; and Stephen Kern, The Culture of Time and Space, 1880-1918 (Cambridge, Mass.: Harvard Univ. Press, 1983).

${ }^{4}$ Timothy Lenoir, "Inscription Practices and Materialities of Communication," in Inscribing Science, ed. Lenoir, pp. 1-19.

${ }^{5}$ Norriss Hetherington, "Percival Lowell: Professional Scientist or Interloper?" Joumal of the History of Ideas, 1981, 42:159-161, on p. 159; and William Heffernan, "The Singularity of Our Inhabited World: William Whewell and A. R. Wallace in Dissent," ibid., 1978, 39:81-100, on p. 81 .
} 
helping explicate diverse claims about the planet through nuanced analyses of literary, ecological, geographical, and visual facets of the debate. Despite their many strengths, however, these accounts have not tended to consider the complex and fluid role of media itself and therefore have not resolved a still-too-simple divide in history of astronomy between "popularizers" who worked in one medium - the periodical press - and a separate class of skeptical "professionals" who predominantly communicated away from the public sphere in scientific journals. ${ }^{6}$ It is a central argument of this essay that a focus on the material technologies that underpinned widespread fascination with Mars during the period around the events of 1892 demonstrates that such simple actor and media classifications are difficult to substantiate. Rather, I will show that the tensions identified by Clerke arose precisely because, at this moment in the history of astronomy, clear divisions between the esoteric realm of astronomical practice and the exoteric realm of public engagement were so uncertain and contested.

At the heart of these tensions were issues of transmission. I suggest in Section I that a new form of "event astronomy" arose out of a novel symbiosis between certain remote astronomical sites and new global telegraphically networked newspapers. In Section II I trace how this relationship fundamentally integrated the telegraph within astronomical practice, shaping how astronomers could work and therefore raising pressing issues for the astronomical community over appropriate and inappropriate methods for making observations travel. Mars featured front and center in these debates, and in Section III I show how the material, temporal, and linguistic constraints imposed by transmission technologies fundamentally shaped what could be said about, and therefore what could be known about, other worlds. An understanding of these effects exposes, I argue, a clearer impression of why Mars came to be seen and understood the way it did in the fin de siècle.

\section{EVENT ASTRONOMY AND TRANSNATIONAL TELEGRAPHIC NEWS}

This section lays the groundwork for understanding the "great Mars boom" by considering the changing relationship between astronomy and the mass media in the decade and a half preceding 1892. I propose a new form of mediatized "event astronomy," emergent from rapid changes both to the practices of astronomy and to the technologies of print news in this era. The section ends by detailing one significant pre-"boom" episode of event astronomy, the eclipse of 1889. This case tellingly illustrates a new symbiotic relationship forged between the key players whose collaboration would lie at the heart of the "great Mars boom."

Common to both the 1889 eclipse and the subsequent furor over Mars three and a half years later was the fact that these were events in the literal sense. They were singular, significant occurrences that took place at a particular time and place. These events' power-their ability to be perceived as such, on a global scale-derived from a novel partnership between two practices that were in their ascendancy in the 1880s: astrophysics and the global telegraphic distribution of news. The practices of the former isolated astronomical work at specific places

\footnotetext{
${ }^{6}$ See, e.g., K. Maria D. Lane, Geographies of Mars: Seeing and Knowing the Red Planet (Chicago: Univ. Chicago Press, 2011), pp. 7-12. I suggest that the categories of "amateur" and "professional" fit awkwardly onto the heterogeneous cast of actors involved in fin-de-siècle debates over life on Mars - and were not used by the actors themselves - and so should be avoided. For recent cultural histories of Mars see also Robert Markley, Dying Planet: Mars in Science and the Imagination (Durham, N.C.: Duke Univ. Press, 2005); Martin Willis, Vision, Science, and Literature, 1870-1920: Ocular Horizons (London: Pickering \& Chatto, 2011), pp. 57-113; Bernard Lightman, "The Visual Theology of Victorian Popularizers of Science: From Reverent Eye to Chemical Retina," Isis, 2000, 91:651-680; Elena Canadelli, “'Some Curious Drawings': Mars through Giovanni Schiaparelli’s Eyes: Between Science and Fiction,” Nuncius, 2009, 24:439-464; Robert Crossley, Imagining Mars: A Literary History (Middletown, Conn.: Wesleyan Univ. Press, 2011); and Jennifer Tucker, Nature Exposed: Photography as Eyewitness in Victorian Science (Baltimore: Johns Hopkins Univ. Press, 2005), pp. 207-233.
} 
and times; the material technologies of the latter facilitated the near-instantaneous transmission of this work internationally.

As historians have chronicled in great detail, the ascendancy of a "new astronomy" in the last four decades of the nineteenth century instituted a profound reorientation of the discipline. As focus was shifted away from the precise mathematical analysis of celestial movements in favor of visual and chemical analysis of celestial bodies, power also shifted decisively from the Old World to the New. Unlike the traditional practices of positional astronomy, a great deal of astrophysical work - from spectrum analysis to photographic and visual investigations of celestial bodies - was fundamentally dependent on massive telescopes. Consequently, from the early 1880s a few giant instruments were constructed and housed at staggering cost in a handful of carefully chosen mountain sites, almost all in the North and South American West. Captured by a zeal for exciting new stellar and planetary discoveries, American philanthropists and entrepreneurs underwrote an entirely new type of observatory, defined by their giant telescopes, cutting-edge laboratory instrumentation, and the rare, exquisite observing conditions assured by their remote, high-altitude locations. I argue in what follows that because planetary mapping in this era relied on these same new sites and technologies, it too should be incorporated alongside spectroscopic and photographic analysis into a capacious definition of fin-desiècle astrophysics as "physical studies of celestial objects."

These changes in favor of a few astrophysical observatories imposed a new geopolitical order on astronomy, affecting both disciplinary practices and the subject's wider relations with its public audiences. Judgment and commentary on positional astronomy necessarily derived from the gradual accumulation and interpretation of data at multiple sites, extending access and explanation across time, space, and an array of actors, ranging from astronomers themselves to philosophers, journalists, commentators, and interested men of science. ${ }^{8}$ In astrophysics, in contrast, it was observing through exceptional, giant telescopes that set the new bar for what qualified as newsworthy, ensuring that the privileged "seeing" power of high-tech remote astronomical sites defined the new entry requirements for astrophysical news. Bound up with changes to the working practices of astronomers, then, were changes to the social conditions of access for those who aspired to chronicle this work. The ability of astrophysical observatories, intentionally located out of sight, to function as news distribution centers would be a central facet of this new high-altitude astronomy.

What made these new enterprises newsworthy extended well beyond the moment of observation, however. By emphasizing the isolation and purity of the remote mountains on which they worked, mountain astrophysicists actively cultivated a new astronomer-adventurer persona that played into the prevailing news economy of the fin de siècle. Highlighting the rugged and demanding character of mountain work helped this new breed to distinguish themselves from metropolitan colleagues, and it tapped into existing popular enthusiasm for accounts of heroic exploration. Complex, challenging, and heroic trips to observe solar eclipses and transits of Venus fit neatly into the prevailing news economy, combining public fascination with periodic astronomical events with the then-dominant narrative of triumphant exploration.

\footnotetext{
${ }^{7}$ I quote here A. J. Meadows's definition in his introduction to the subject, "The Origin of Astrophysics," in Astrophysics and Twentieth-Century Astronomy to 1950: Part A (Cambridge: Cambridge Univ. Press, 1984), ed. Owen Gingerich, pp. 3-15, on p. 3. On the rise of astrophysics and its U.S. domination see, in addition, John Lankford, American Astronomy: Community, Careers, and Power, 1859-1940 (Chicago: Univ. Chicago Press, 1997); and Catherine Nisbett, "Business Practice: The Rise of American Astrophysics, 1859-1919” (Ph.D. diss., Princeton Univ., 2007). On mountain astronomy see Lane, Geographies of Mars, pp. 65-139; and Catherine Nisbett Becker, "Professionals on the Peak," Science in Context, 2009, 22:487-507.

${ }^{8}$ See, e.g., Simon Schaffer, "The Nebular Hypothesis and the Science of Progress," in History, Humanity, and Evolution: Essays in Honour of John C. Greene, ed. J. R. Moore (Cambridge: Cambridge Univ. Press, 1989), pp. 131-164.
} 
In an era of mass readership, astronomers and the journalists who covered them "wrote for a public that liked reading about travel, adventure, cheerful success over adversity, and the exotic." Astronomers, like polar explorers, therefore sought to represent themselves as "masculine heroes, adventurous travellers, and scientific explorers," an image that the press was more than happy to promote. ${ }^{9}$ By the 1880 s competition in the United States for newspaper readers was fierce, and the securing of exclusive coverage of the new American astronomical mountain expeditions joined other forms of exploration and adventure reportage as a prized technique for capturing sales.

One newspaper, above all, sought to dominate this travel and adventure market. By the 1880s the New York Herald was the highest-circulation newspaper in the United States. As the most successful product of the "penny press" revolution of 1830s New York, the Herald was a populist, sensationalist, progressive organ that had long prided itself on its unparalleled newsgathering capabilities. Under the stewardship of the irascible and combative James Gordon Bennett, and then his namesake son, the paper had pioneered many of the industry's technological and organizational innovations, including pony expresses, harbor newsboats, lightning presses, dedicated telegraph lines, and the incorporated press agency. Above all, though, it was the paper's unrivaled network of international correspondents that set it apart from its competitors. From its earliest days, the elder Bennett had committed his paper to an international scope, and by the 1860s it had regular and special correspondents in at least twelve countries on four continents. This news was gathered at lightning pace by exploiting the costly new technology of submarine telegraphy, with the Herald repeatedly outmaneuvering its rivals in the fierce marketplace of international news transmission. ${ }^{10}$ Bennett, Jr., built on his father's legacy, focusing much of his paper's energies on covering, and in many instances generating, spectacular news of adventure, exploration, and scientific discovery. When he dispatched Henry Morton Stanley into Africa to find David Livingstone, the younger Bennett is reported to have given his correspondent an unlimited budget, explaining that he intended to "publish whatever news will be interesting to the world at no matter what cost." ${ }^{11}$ His paper sponsored polar expeditions, helped pioneer meteorological prediction as a news commodity, and ran competitions to promote the development of automobiles and powered flight - and it offered both coverage of and tangible support to a variety of astronomical expeditions.

\footnotetext{
${ }^{9}$ Alex Soojung-Kim Pang, "The Social Event of the Season: Solar Eclipse Expeditions and Victorian Culture," Isis, 1993, 84:252-277, on p. 268; and Lane, Geographies of Mars (cit. n. 6), p. 100. On the confluence of science, triumphant exploration, and mass media see also K. Maria D. Lane, "Astronomers at Altitude: Mountain Geography and the Cultivation of Scientific Legitimacy," in High Places: Cultural Geographies of Mountains, Ice, and Science, ed. Denis Cosgrove and Veronica Della Dora (London: Tauris, 2009), pp. 126-144; Alistair Sponsel, "Constructing a 'Revolution in Science': The Campaign to Promote a Favourable Reception for the 1919 Solar Eclipse Experiments," Brit. I. Hist. Sci., 2002, 35:439-467; Beau Riffenburgh, The Myth of the Explorer: The Press, Sensationalism, and Geographical Discovery (London: Belhaven, 1993); Pang, Empire and the Sun: Victorian Solar Eclipse Expeditions (Stanford, Calif.: Stanford Univ. Press, 2002); and Jessica Ratcliff, The Transit of Venus Enterprise in Victorian Britain (London: Pickering \& Chatto, 2008).

${ }^{10}$ James L. Crouthamel, Bennett's "New York Herald" and the Rise of the Popular Press (Syracuse, N.Y.: Syracuse Univ. Press, 1989); Menahem Blondheim, News over the Wires: The Telegraph and the Flow of Public Information in America, 1844-1897 (Cambridge, Mass.: Harvard Univ. Press, 1994); Richard O'Connor, The Scandalous Mr. Bennett (Garden City, N.Y.: Doubleday, 1962); Dwayne Winseck and Robert Pike, Communication and Empire: Media, Markets, and Globalization, 1860-1930 (Durham, N.C.: Duke Univ. Press, 2007), pp. 43-91; and Richard A. Schwarzlose, The Nation's Newsbrokers, 2 vols. (Evanston, Ill.: Northwestern Univ. Press, 1989, 1990).

${ }^{11}$ Henry M. Stanley, How I Found Livingstone: Travels, Adventures, and Discoveries in Central Africa (London: Sampson Low, Marston, Low, \& Searle, 1872), p. xviii. See also Riffenburgh, Myth of the Explorer (cit. n. 9), pp. 56-68. On the Herald's generation and coverage of spectacular news more generally see ibid., pp. 49-137. By the 1880s "exploration had become one of the main staples of The Herald" (p. 84).
} 
The Herald's most successful partner in this enterprise was the Harvard College Observatory. Under the careful stewardship of its enterprising and exacting director, Edward C. Pickering, Harvard Observatory had risen by the 1880s to a position of preeminence in the nascent discipline of astrophysics. ${ }^{12}$ Pickering's ambitious program of stellar mapping, photometry, and spectroscopy was not well suited, however, to the poor seeing conditions of Cambridge, Massachusetts, and it faced the immediate threat of technological obsolescence in the face of America's first permanent mountain observatory, California's Lick Observatory. Built on Mount Hamilton outside San Francisco between 1876 and 1888, the Lick Observatory captured perfectly the new Zeitgeist of mountain astronomy. It was funded by the eccentric land baron James Lick, whose huge $\$ 700,000$ bequest stipulated specifically that his new observatory possess a telescope "superior to and more powerful than any . . yet made." Harvard's response to this western threat was the pursuit of the Boyden Fund, left in 1879 by the Massachusetts engineer and inventor Uriah Atherton Boyden to establish an observatory for "conducting astronomical observations at such a height as to be free, so far as possible, from the injurious effects due to the atmosphere."13 After a strenuous five-year campaign Pickering secured the fund for Harvard in February 1887, just as the Lick neared completion. With no viable mountain location within easy reach of Cambridge, expeditions were sent out to scout potential sites for a new permanent sister observatory, with locations surveyed and tested in Colorado, southern California, and Peru. ${ }^{14}$ Thus began Harvard's entry into the new realm of astronomical exploration, with the Herald at the forefront of chronicling and promoting Harvard Observatory's ambitious plans. The astronomers sent west to climb mountains and test sites were, the Herald wrote, "undaunted soldiers of science," their initial results "far surpass[ing] the most sanguine expectations." 15

Considerable promotional work by astronomers and observatory directors made this sort of positive reportage happen. Proactively nurturing relationships with the press helped raise personal profiles and, just as important, money for new, high-cost astrophysical institutions. ${ }^{16}$ Fostering close relations with newspapers like the Herald also benefited the practical execution of scientific expeditions. This was particularly evident in the case of Harvard Observatory's 1889 eclipse expedition, which was run by the very astronomer in charge of finding a site for the Boyden Station, Edward Pickering's younger brother William. ${ }^{17}$ A keen mountaineer, William was an archetype of a new breed, the astronomer-adventurer. At once field scientists, precision

\footnotetext{
${ }^{12}$ Bessie Zaban Jones and Lyle Gifford Boyd, The Harvard College Observatory: The First Four Directorships, 1839-1919 (Cambridge, Mass.: Harvard Univ. Press, Belknap, 1971) (hereafter cited as Jones and Boyd, Harvard College Observatory), pp. 176444; and Nisbett, "Business Practice" (cit. n. 7).

${ }^{13}$ Helen Wright, James Lick's Monument: The Saga of Captain Richard Floyd and the Building of the Lick Observatory (Cambridge: Cambridge Univ. Press, 1987), pp. 28, 117-120; and Nisbett, "Business Practice," p. 52 (Boyden specifications).

${ }^{14}$ Nisbett Becker, "Professionals on the Peak" (cit. n. 7); Jones and Boyd, Harvard College Observatory, pp. 246-268; Nisbett, "Business Practice," pp. 52-95; and Howard Plotkin, "Harvard College Observatory's Boyden Station in Peru: Origin and Formative Years, 1879-1898," in Mundialización de la ciencia y cultura nacional: Actas del congreso internacional "Ciencia, descubrimiento y mundo colonial," ed. A. Lafuente, A. Elena, and M. L. Ortega (Madrid: Doce Calles, 1993), pp. 689-705.

15 "Stars' Strange Secrets Shown to Astronomers," New York Herald, 19 Oct. 1889, p. 5. Other examples of this wide press coverage include "Prof. W. H. Pickering," New York Evening Post, 26 Jan. 1889, p. 9; "Photographing the Southern Heavens," New York Sun, 30 Mar. 1890, p. 15; and "Mapping the Southern Sky from a Mountain Peak Fourteen Thousand Feet High," Scientific American, 1891, 64:36

${ }^{16}$ Edward Pickering was a famously prodigious fundraiser, who went so far as to hire a public relations expert, George Michaelis, to manage his observatory's newspaper coverage. See Howard Plotkin, "Edward C. Pickering and the Endowment of Scientific Research in America, 1877-1918," Isis, 1978, 69:44-57; and Lankford, American Astronomy (cit. n. 7), p. 189.

${ }^{17}$ Good biographical detail on William Pickering's idiosyncratic career can be found in Jones and Boyd, Harvard College Observatory; and Howard Plotkin, "William H. Pickering in Jamaica: The Founding of Woodlawn and Studies of Mars," Lournal for the History of Astronomy, 1993, 24:101-122.
} 
observers, and adventurer-geographers, such men had to manage a blurred identity as well as organize an array of complex travel and scientific pursuits. Collaboration with the press not only bolstered this nascent identity formation; it also placed important logistical and technical assistance at these astronomers' disposal. The eclipse of 1 January 1889 proved to be exemplary of this symbiosis, and it helped forge a relationship between William Pickering and the Herald that would have a profound impact on his subsequent work in 1892.

In a stroke of luck for Harvard Observatory, the 1889 eclipse placed northern California in the path of totality. Edward Pickering had tended to have a dim view of weather-dependent eclipse expeditions, but in this instance he consented to a less risky dual-purpose field trip. William would first lead a party to observe the eclipse in the north of the state, before moving on to Wilson's Peak in the south to scout the mountain as a potential site for the Boyden Station. Like his older brother, William was very much aware of the need to publicize his expedition widely; but in contrast to Edward's always careful and austere manner, the more precocious William approached these events with the brash swagger of a showman adventurer.

To view the eclipse, William and his party settled on the town of Willows, north of Sacramento. But rather than engage a press officer to travel with the party and report on his behalf, William devised a bold first in eclipse observation reporting: direct, first-person, real-time telegraphic broadcasting from the site of observation itself. Through Western Union and the Herald, William organized a dedicated telegraph line that ran uninterrupted from his temporary observing station directly into the Herald's office in New York. Financially, this high-tech enterprise was covered by the newspaper in return for a guaranteed exclusive. In return, William secured both personal publicity and, crucially, access to a dedicated time signal. The latter was regulated by a chronometer set up in the Herald office and managed by the Amherst College astronomer David Todd, who sat in New York and signaled directly to William using a prearranged cipher. The Herald, by return message, printed up William's reports of the event as telegraphic transcripts, complete with datelines that contained the precise time of transmission, down to the minute. Exploiting the medium, William composed these telegrams to read like explorers' dispatches, breathlessly describing the team's visual, photographic, and photometric observations of a corona "extending outwards from the sun ... two millions of miles." But he also went out of his way to note the scientific advantage of the telegraphic time signal, which secured the exact times of geometric contact, determining the duration of totality as 118 seconds - "three seconds longer than the predicted duration." 18 Although astronomers from numerous observatories had traveled to observe the eclipse, by uniquely exploiting the transmission technologies provided by the Herald-dedicated telegraph lines, rapid print and distribution networks, syndicated replication of the dispatches across most U.S. cities, reproduction in the Herald's Paris edition -William Pickering had secured his own exclusive, as the first named astronomer to present his observations and discoveries in a public forum.

The impact of this collaboration endured long after the eclipse itself. In the following weeks the Herald spent as much space crowing about its exclusive setup as it had reporting on the event. In explaining the technical details of the telegraph setup, the paper boasted that "the combination of newspaper energy, astronomical learning and telegraphic speed was never better shown than in the Herald's plans for reporting this great scientific event." A day later, this self-promotion was augmented by commendations rounded up from half a dozen eminent men of science. Simon Newcomb agreed that "the Herald had done a wonderful service to science." Asaph Hall declared that "the Herald has set an admirable example in collecting

\footnotetext{
${ }^{18}$ William Pickering, "Harvard's Success at Willow," N. Y. Herald, 2 Jan. 1889, p. 3; “How the News Was Gathered," ibid., p. 3; and "The Hidden Sun," ibid., 3 Jan. 1889, p. 3.
} 
and publishing so promptly reports of the eclipse." George Barker admitted that "all his information about the eclipse had been derived from the Herald." As with reports of crime or society scandal, exclusives burnished a paper's reputation as preeminent in the art and craft of news gathering. But more than this, the excitement of a discrete and rare astronomical event was here combined with sensationalist reporting of scientific exploration to produce a media phenomenon, in which the press could lay claim to being an active agent in discovery. David Todd's lively first-person account of the enterprise for the Century magazine was entitled "How Man's Messenger Outran the Moon," and it was accompanied by an illustration depicting this scientific news triumph - the line of totality sweeping across the North American continent, overshadowing literally but not figuratively an even greater line below it: that of the Herald's telegraph wire straddling the entire breadth of the country. ${ }^{19}$ (See Figure 1.)

These links between the Herald and William Pickering, once established as mutually beneficial, would endure. Crucially, the two parties would collaborate again in the more remote environment of South America. This continent was rapidly becoming the distinct dominion of the Herald in terms of English-language news, with the paper pouring money into correspondents and telegraph networks in a concerted effort to monopolize the region's news output north into the United States and Europe. At a time of growing U.S. imperial intervention in South America, Bennett, Jr., styled himself as a "sort of ex-officio, one-man state department," utilizing his correspondents to bolster the U.S.'s "Big Sister" policy of active political and business intervention in the region. ${ }^{20}$ In 1891, in a move that would have a profound impact on the "great Mars boom," James Scrymser's Central and South American Telegraph Company extended its fledgling cable network south of Lima as far as Valparaíso, Chile, and then across to Argentina. Bennett, Jr., immediately negotiated an exclusive news-transmission deal on Scrymser's cables, effectively cornering the U.S. market for telegraphic news from South America. "To say that the governments and press, as well as the reading public of both America and Europe have depended on [our] despatches for South American news, is simply to state a fact universally known and recognized," gloated the Herald. ${ }^{21}$

This monopoly naturally extended to astronomical expeditions too. When William Pickering led another eclipse expedition, this time to a remote mountain site in Chile, the Herald's local correspondent, Henry Wolfe, assisted with travel arrangements and accompanied the party. The New York and Paris Herald were thus able to report the eclipse observations of William's party in detail the morning after the event, a news distribution coup that the French Academy of Sciences dubbed "unparalleled."22 Edward, back in Cambridge, when pressed for comment declared himself "amazed and delighted at the feat of the Herald"; without the

\footnotetext{
19 "How the News Was Gathered"; "Delighted Scientists: The Herald's Enterprise and Its Results Commended," N. Y. Herald, 3 Jan. 1889, p. 3; and David Todd, "How Man's Messenger Outran the Moon," Century, 1889, 38:602-606, rpt. as "The Moon Distanced,” N. Y. Herald, 4 Aug. 1889, p. 22.

${ }^{20}$ O'Connor, Scandalous Mr. Bennett (cit. n. 10), p. 184. On post-1880 U.S. imperial intervention in South America see Walter LaFeber, The Cambridge History of American Foreign Relations, Vol. 2: The American Search for Opportunity, 1865-1913 (Cambridge: Cambridge Univ. Press, 1993), pp. 60-82; and Sidney Lens, The Forging of the American Empire: From the Revolution to Vietnam: A History of U.S. Imperialism (London: Pluto, 2003), pp. 159-162.

21 "The Central and South American Telegraph and the Herald's News," N. Y. Herald, 30 May 1893, p. 8; and Crouthamel, Bennett's "New York Herald" and the Rise of the Popular Press (cit. n. 10), pp. 48-50, 56-68, 138-141. For more on Scrymser's cable network see Winseck and Pike, Communication and Empire (cit. n. 10), pp. 77-80; Jorma Ahvenainen, The European Cable Companies in South America (Helsinki: Academia Scientiarum Fennica, 2004), pp. 96-114; Victor M. Berthold, History of the Telephone and Telegraph in Chile, 1851-1921 (New York: AT\&T, 1924), pp. 30-33; and "Cable Laying Record Broken," N. Y. Herald, 30 May 1893, p. 10.

22 “The Herald's Eclipse News on Two Continents," N. Y. Herald, 18 Apr. 1893, p. 8. The Herald published at least twelve pieces on the eclipse between 16 February and 9 June.
} 


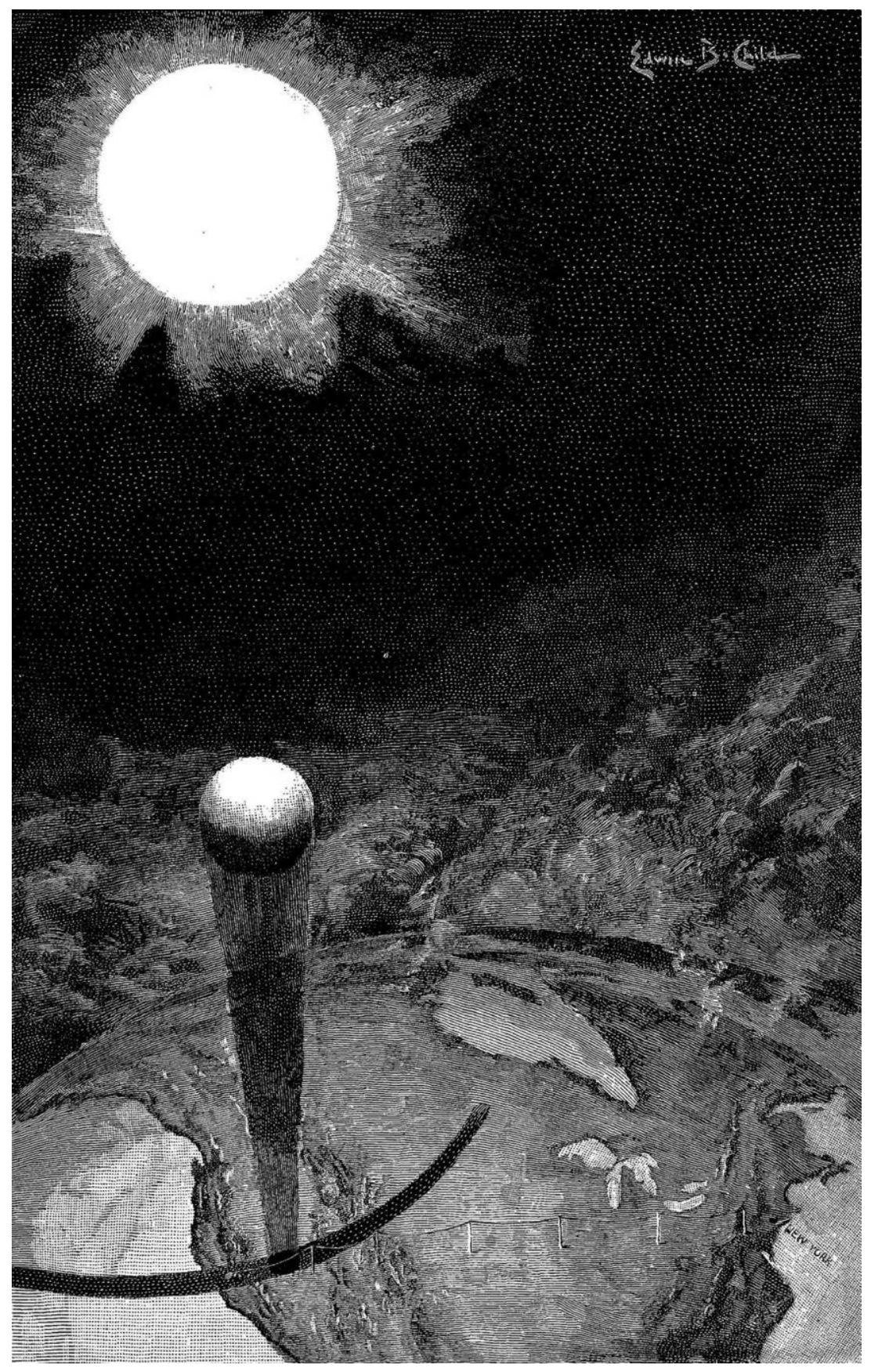

Figure 1. The 1889 eclipse, as illustrated in David Todd's account for the Century magazine, showing both the path of totality and the Herald's dedicated transcontinental telegraph line. Todd's article began: "It came about on this wise-rather complexly. Sun and moon, types and wires,astronomy, journalism, and telegraphy,-all were concerned in the contest." From David Todd, "How Man's Messenger Outran the Moon," Century, 1889, 38:602-606, on p. 606. 
budget to communicate with his brother via telegraph, he had been left otherwise dependent on "the slow course of the mails." "The Herald," boasted the paper, "is always to be depended on to come to the rescue of impoverished science." ${ }^{23}$ Harvard's remote astronomical sites thus entered into a symbiotic relationship with the internationally networked Herald, establishing a new power dynamic that underpinned a new form of "event astronomy."

\section{REPORTING WILLIAM PICKERING'S 1892 OBSERVATIONS OF MARS}

At no time was this close relationship between astronomy, journalism, and telegraphy more spectacularly evident than in the middle months of 1892, when William Pickering's observations of Mars from Harvard's newly established South American station became the central moment of the "great Mars boom." This section provides a detailed and tightly focused account of the "boom" in terms of its serialized, global transmission. I trace in chronological detail the specifics of how observations made at a particular time and place were transcribed, transmitted, and translated into internationally distributed and consumed accounts, exposing the practices and controversies that emerged from event astronomy's melding of scientific and media cultures.

After a thorough and at times intrepid search across two continents, Harvard Observatory selected the remote mountain site of Arequipa, Peru, for its Boyden Fund outstation. Following the success of the 1889 eclipse field trip, Edward Pickering chose his younger brother as the man to establish the new observatory. Unsurprisingly, the Herald covered the project assiduously from the outset, trumpeting William's mission to Peru as "probably the best equipped" and "the most comprehensive scientific expedition ever sent forth." Singled out for praise were the Arequipa site's "transparent Andean skies" and "fine instruments."24

As historians have chronicled, once William arrived in January 1891 to replace the advance party things rapidly got out of hand, with Edward's conservative plans for a relatively cheap, modest outpost completely ignored by his headstrong brother. Sent out with instructions to spend no more than $\$ 500$ on the site initially, upon arrival William proceeded to buy up large tracts of land and build himself an extravagant house, quickly blowing well past his meager budget. ${ }^{25}$ To make matters worse, William's excessive spending did not appear to be producing concrete results, and by the end of 1891 Edward still had not received any appreciable quantity of data or photographic plates from his outstation. While Edward's plan was for the Arequipa site to serve Harvard Observatory's ambitious long-term project of systematic photometry and spectroscopy, William, it transpired, had entirely different intentions. Rather than undertaking the laborious and unglamorous survey work with which he had been charged, he decided to concentrate instead on visual observation of the planets. Mars was about to come into perihelic opposition; and, as Edward should have known, this planet had long held a fascination for his brother.

As with eclipses, Mars's surface could be observed only periodically, in a consistent cycle of "oppositions." Generally too distant to scrutinize, the planet made its closest approach to Earth for a few weeks roughly once every two years. Unlike eclipses, however, favorable "oppositions" vary considerably in quality. The very best "perihelic" conditions-combining closest approach with brightest illumination-occur only once every fifteen years; thus the middle months of 1892 offered the finest occasion for observing Mars since 1877.

\footnotetext{
23 "Results of the Sun's Eclipse," N. Y. Herald, 18 Apr. 1893, p. 9.

24 “To Map Out the Starry Heavens," N. Y. Herald, 15 Dec. 1890, p. 4; and "Harvard's Astronomical Expedition,” ibid., p. 6.

25 Donald Fernie, The Whisper and the Vision: The Voyages of the Astronomers (Toronto: Clarke, Irwin, 1976), pp. 173-179. Nisbett, "Business Practice" (cit. n. 7), notes that by the end of his first year in Peru William had spent $\$ 22,000$ and had budgeted $\$ 12,000$ more for the coming year. For historians' accounts see Jones and Boyd, Harvard College Observatory, pp. 246-268, 287-324; Nisbett, "Business Practice," pp. 37-38, 52-150; Plotkin, "Harvard College Observatory's Boyden Station in Peru" (cit. n. 14); Nisbett Becker, "Professionals on the Peak" (cit. n. 7); and Lane, Geographies of Mars (cit. n. 6), pp. 107-115.
} 
The sense that this was a discrete and significant event was greatly heightened by two related factors. On the one hand, the rise of astrophysics had, as we have seen, given rise to a very few new supermassive telescopes whose seeing power far exceeded anything pointed toward Mars in 1877. And on the other hand, astronomical interest in and public curiosity about the physical geography of Mars had increased considerably in the preceding decade, stoked by a number of competing remappings of the planet's surface issued in the wake of the 1877 opposition. As K. Maria D. Lane has shown, the authority of these maps derived in part from their increased levels of detail, with the Italian astronomer Giovanni Schiaparelli ultimately winning assent for his successively more abstract and geometrical cartographic representations of the planet's surface. (See Figure 2.) Novel to these maps were the "canali," an intricate network of straight,

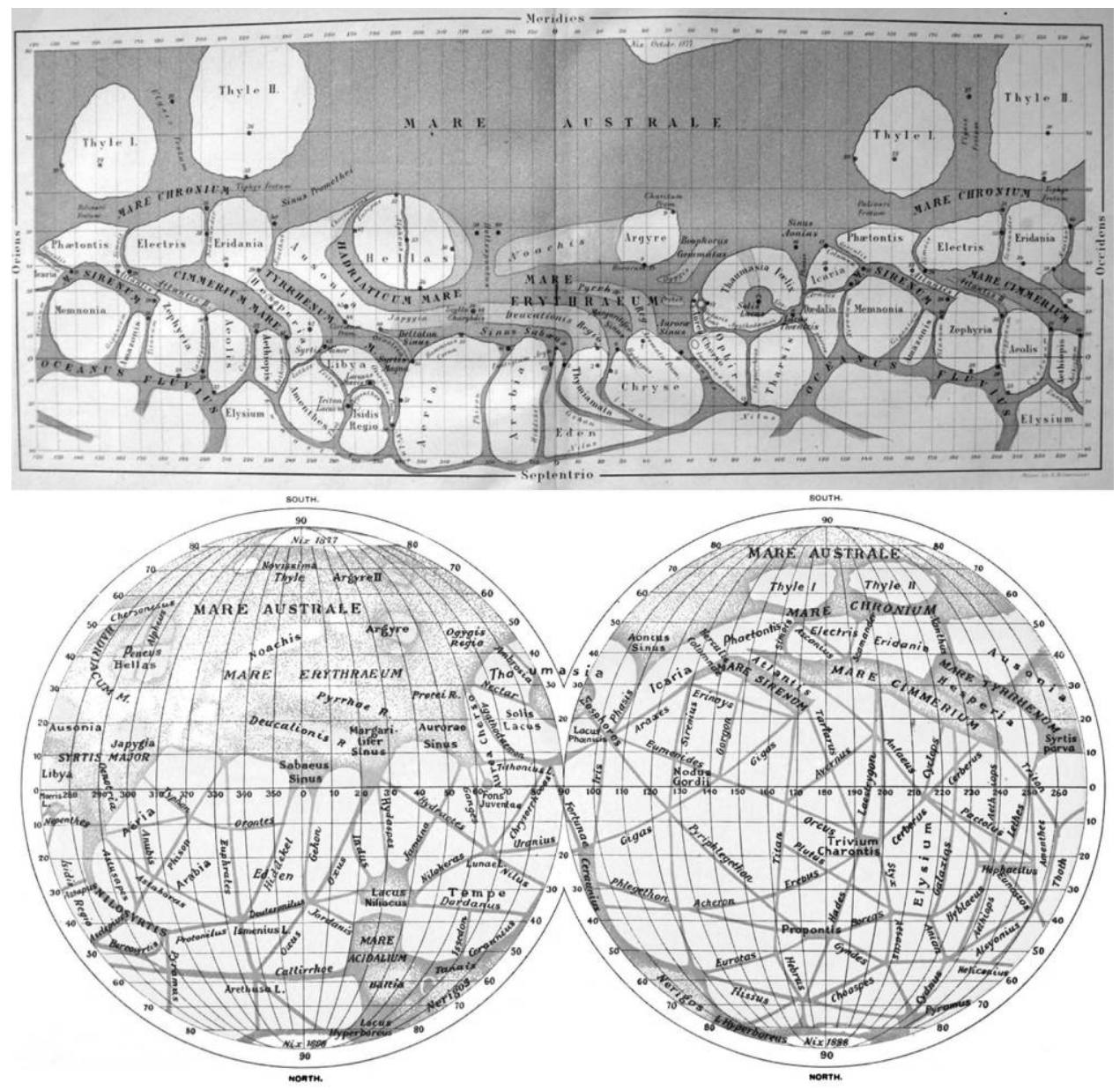

Figure 2. Giovanni Schiaparelli's first map of Mars (top), based on his observations made during the perihelic opposition of 1877 , is the first to show his distinctive "canali" - numerous narrow waterways running between island landmasses. From Giovanni Schiaparelli, "Osservazioni astronomiche e fisiche ... del pianeta Marte ... durante l'opposizione del 1877," Atti della Reale Academia dei Lincei, 1878, 3(2):1-136, Plate 3. By 1888 Schiaparelli had updated his map (bottom) to show the canali as distinctively straight, dark lines that intersected the landmass that dominated the northern hemisphere of the planet. From Astronomy and Astro-Physics, 1894, 13, Plate 19. 
dark lines that crisscrossed the planet, often converging at points. Never seen collectively, but frequently resighted individually or in parallel pairs by various astronomers throughout the 1880s, reports of these curious features fueled increasing speculation about their nature. Though a variety of terrestrial analogies were posited, from geological fissures to rivers or bands of vegetation, a growing number of astronomers and popular commentators began at least to entertain the idea that they might be artificial in origin. ${ }^{26}$

With his flair for the extravagant and newsworthy, William naturally gravitated to Mars as a subject of research. Since 1888 he had focused more and more attention on the planet, and his growing publication output on its enigmatic physical constitution fed on the ever-growing public interest in the subject. ${ }^{27}$ The Herald, as with the eclipse, took an active interest, and their international scope again proved significant. Starting in August 1890 the newspaper began publishing, through its Paris edition, regular pieces on both sides of the Atlantic by the French astronomer and author Camille Flammarion. Though he was spectacularly famous in his own country, this was likely the first time that many American and British readers would have read his work. Like his famous British counterpart Richard Proctor, Flammarion was a committed populist with a particular interest in life on Mars, and like Proctor he was a master at speculating playfully about plurality while maintaining a public reputation as a serious astronomer. His first book, La pluralité des mondes habités (1862), was already in its thirty-third edition by 1890, establishing him as a major figure in pluralist debates. ${ }^{28}$ His bold and conjectural style fit the Herald perfectly. In a 16 September piece entitled "News from the Planet Mars," the Herald gleefully reported that Flammarion's article of the previous day "strongly hints that his new observations indicate the agency of intelligent creatures on Mars." No doubt to the Herald's delight, this launched Flammarion straight into a confrontation with the Lick's skeptical director, Edward Holden, who, despite confirming that observers at his observatory had seen some of Schiaparelli's canals, urged extreme caution when it came to drawing conclusions as to their nature and significance. ${ }^{29}$

Such debates exposed a growing tension between sensation-seeking news outlets and those practitioners of astrophysics who wished to protect the rigor and sobriety of their nascent discipline. Media choices mattered a great deal in these conflicts. In his reply to Flammarion, Holden made clear his distaste at being drawn into a mass-media forum. "The details of scientific evidence cannot be discussed in the columns of a daily newspaper," he sullenly telegraphed to the Herald, as "the proper place for such a discussion is in an astronomical journal before a jury of experts." ${ }^{30}$ But it was precisely this issue of how and where expert astrophysical testimony should be circulated that remained ambiguous. Undeterred by Holden's rebuke,

\footnotetext{
${ }^{26}$ Lane, Geographies of Mars, pp. 23-63. On the history of the early mapping of Mars and its canals see also Sheehan, Planet Mars (cit. n. 1), pp. 58-97; Crowe, Extraterrestrial Life Debate (cit. n. 1), pp. 480-502; and the works cited in note 6, above.

${ }^{27}$ William Pickering, "The Physical Aspect of the Planet Mars," Science, 1888, 12:82-84; W. Pickering, "Visual Observations of the Surface of Mars," Sidereal Messenger, 1890, 9:369-370; and W. Pickering, "Photographs of the Surface of Mars," ibid., pp. $254-255$.

${ }^{28}$ Crowe, Extraterrestrial Life Debate (cit. n. 1), pp. 367-386; Markley, Dying Planet (cit. n. 6), pp. 59-60; and Bernadette Bensaude-Vincent, "Camille Flammarion: Prestige de la science populaire," Romantisme, 1989, 65:93-104. On Proctor and Mars see also Joshua Nall, "News from Mars: Transatlantic Mass Media and the Practice of New Astronomy, 1870-1910” (Ph.D. diss., Univ. Cambridge, 2013), Ch. 1.

29 "Peculiar Events in Mars," N. Y. Herald, 15 Sept. 1890, p. 7; and "News from the Planet Mars," ibid., 16 Sept. 1890, p. 6 (quotation). For the confrontation with Holden see "Other Worlds than Ours," ibid., 6 Oct. 1890, p. 7; and "Strange Phenomena Observed on Mars," ibid., 7 Oct. 1890, p. 6.

30 "What Professor Holden Says," N. Y. Herald, 9 Oct. 1890, p. 7. See also Edward Holden, "Notes on the Opposition of Mars, 1890," Publications of the Astronomical Society of the Pacific, 1890, 2:299-300.
} 
the Herald's Boston correspondent approached William Pickering for comment on the affair. $\mathrm{He}$, much more so than his older brother, saw his own role as an expert as commensurate with vibrant speculation in public forums. By employing a Flammarion-esque degree of ambiguity and conjecture, his reply to the Herald stoked the sensation further by intimating that he saw Mars as an aged, dying planet that was (in the Herald's words) "largely uninhabitable." ${ }^{11}$ Such enigmatic statements, when printed under the sensational headline "THE PLANET MARS IS NIGH TO DEATH," will doubtless have consternated Holden (and likely Edward Pickering too), but they also cast William as a central character in the growing saga over the question of life on the planet. By the time he sailed for Peru in December, the Herald was excitedly proclaiming that "perhaps the most interesting discoveries to reward Professor Pickering will be the nature of the canals of Mars when the ruddy planet in 1892 makes his nearest approach to the earth."”22

Once settled in Arequipa, William appeared to concur. Ignoring his photographic assignments and repeated pleas from Edward to send back negatives, by mid-1891 William was enthusiastically extolling the superior seeing conditions at his mountain outpost, especially with respect to visual observation of the planets. Mars was approaching, and William wrote to his brother excitedly, predicting big things for the coming perihelic opposition: "Here with the fine seeing, and the southern declination of the planet, I am quite sure I should see more, and if so, probably more than anybody has ever seen before. There will not be another equally good opportunity for fifteen years. I think it should not be missed." ${ }^{33}$

William felt justified in choosing visual over photographic techniques because he believed that a skilled observer like himself could make out more detail on Mars's surface during fleeting moments of exceptional seeing than long-exposure photographs could ever reveal. His unique location afforded him an opportunity to make a name for himself with new and exciting discoveries, and it is clear that he regarded this visual work on Mars as a form of exploration. To his mother he wrote:

I have been very busy upon Mars this week, I begin to feel quite at home upon the planet, and feel as if I could quite find my way about upon it anywhere. Last night I discovered a new lake that is not shown upon any of the maps. . . It is very interesting, and I look forward to each night's work with as much interest as if I could really visit the countries I am looking at.

"In the four hundredth year from Columbus," he wrote in another letter, "we feel as if we too were almost discovering a new country." ${ }^{34}$

\footnotetext{
31 “The Planet Mars Is Nigh to Death," N. Y. Herald, 9 Oct. 1890, p. 7. As the two papers had a syndicate agreement, much of this article also appeared on the same day in Holden's local paper, the San Francisco Chronicle, p. 1. On the trope of Mars as a dying planet see Markley, Dying Planet (cit. n. 6).

32 “Harvard's Astronomical Expedition," N. Y. Herald, 15 Dec. 1890, p. 6.

${ }^{33}$ William Pickering to Edward Pickering, 1 June 1891, Harvard College Observatory, Records of Director Edward C. Pickering, HOLLIS No. 001966647, Harvard University Archives, Cambridge, Mass. Quoted courtesy of the Harvard University Archives. Regarding William's enthusiasm for the seeing conditions at Arequipa see William Pickering, "Astronomical Possibilities at Considerable Altitudes," Astronomische Nachrichten, 1892, 129:98-99; and Plotkin, "Harvard College Observatory's Boyden Station in Peru" (cit. n. 14), pp. 700-703.

${ }^{34}$ W. Pickering to Charlotte Pickering, 17 July 1892, 31 July 1892, Papers of William H. Pickering, HOLLIS No. 000604354 , Harvard University Archives. Quoted courtesy of the Harvard University Archives. For William's confidence in his visual techniques see William Pickering, "Investigations in Astronomical Photography," Annals of Harvard College Observatory, 1895, 32:1-115, on p. 109; Plotkin, "Harvard College Observatory's Boyden Station in Peru," p. 701; and Jones and Boyd, Harvard College Observatory, p. 304.
} 
William himself was isolated from most of the international coverage of the 1892 opposition, though he might have suspected the press excitement that was beginning to build. Interest from newspapers and periodicals was stoked, in particular, by a sudden sensation-promoted by Flammarion through the Herald - concerning the possibility of sending and receiving visual signals to and from Mars's inhabitants. ${ }^{35}$ As a cultural phenomenon, interplanetary communication spoke of a powerful symbiosis between public fascination with life on Mars and massive interest in instantaneous, long-distance forms of communication-be it telegraphy, the telephone, spiritualism, or newfangled "wireless" signals. ${ }^{36}$ Edison's first patent for a wireless telegraph system was issued in December 1891, and Flammarion explicitly linked Edison's experiments with projects of interplanetary communication. The topic received enough attention to draw a satire from Punch, which published "Extracts from the Note-book of the Secretary of the Earth and Mars Intercommunication Company, Limited." ${ }^{37}$ While some men of science took the subject seriously - for example, Francis Galton, who wrote to the Times on the matter-others, such as an anonymous editorial in the Journal of the British Astronomical Association, lamented that "the leading idea in several papers seemed to be the prospect of starting an interplanetary telegraph." 38

The challenges and promises of interplanetary communication overlapped with the concerns of terrestrial long-distance messaging. Edward Pickering, stuck in Cambridge, Massachusetts, struggled with the problem of what to do with his wayward, free-spending brother. In the spring of 1892, two months before the Martian opposition, he finally made up his mind. In late May, after much commotion among the Harvard Corporation that administered the Boyden Fund, Edward wrote a long and stern letter to William explaining that he was being recalled permanently, to be replaced by Solon Bailey in early 1893. With debt piling up and little in the way of data returned to Cambridge, Edward forlornly conceded that William was likely to continue with his own personal work, rather than concentrating on generating systematic data and photographs for astronomers at Harvard to process and analyze. "As the routine work with the 13 inch cannot advance very far this year and must be mainly done by Mr. Bailey, there is no reason why you should not make rather more visual observations than formerly proposed." 39

William was both shocked and deeply upset by Edward's decision, and the relationship between the brothers began to disintegrate. Greatly complicating matters was the considerable time lag inherent to communication by post. Mail took about a month to get between Cambridge and Arequipa, and the observatory could not afford to use the telegraph except for

\footnotetext{
35 “Invisible Worlds," N. Y. Herald, 4 June 1891, p. 6; "Long Distance Signals," ibid., 12 July 1891, p. 13; "How to Talk with the Folks on Mars," ibid., 3 Jan. 1892, p. 7; and "Possibilities of Planetary Inhabitants," ibid., 29 May 1892, p. 30. See also Crowe, Extraterrestrial Life Debate (cit. n. 1), pp. 393-400; Lane, Geographies of Mars (cit. n. 6), pp. 197-201; and Crossley, Imagining Mars (cit. n. 6), pp. 58-65.

${ }^{36}$ Carolyn Marvin, When Old Technologies Were New: Thinking about Electric Communication in the Late Nineteenth Century (New York: Oxford Univ. Press, 1988), pp. 184-190; and Jeffrey Sconce, Haunted Media: Electronic Presence from Telegraphy to Television (Durham, N.C.: Duke Univ. Press, 2000), pp. 95-103. Spiritualist communication with Martians would become a hot topic. See, e.g., "News from Mars: Alleged Communications by a Martian 'Control," Borderland, 1897, 4:406-409; and Robert Crossley, "Mars and the Paranormal," Science Fiction Studies, 2008, 35:466-484.

${ }^{37}$ Camille Flammarion, "Inter-Astral Communication," New Review, 1892, 6:106-114; and "Reading the Stars a la Mode," Punch, 20 Aug. 1892, p. 78.

38 "Notes: The Opposition of Mars," Journal of the British Astronomical Association, 1892, 2:477; Francis Galton, "Sun Signals to Mars [Letter to the Editor]," London Times, 6 Aug. 1892, p. 7; and “Earth May Signal Mars," New York Times, 7 Aug. 1892, p. 5. Galton's comments drew the ire of Norman Lockyer, "The Opposition of Mars," Nature, 1892, 46:443-448.

${ }^{39}$ E. Pickering to W. Pickering, 29 May 1892, quoted in Jones and Boyd, Harvard College Observatory, p. 309.
} 
the briefest and most urgent of messages..$^{40}$ This delay gave William a significant degree of freedom, which he exploited to his own advantage. As Catherine Nisbett Becker's account of Harvard Observatory's initial U.S. high-altitude expeditions stresses, the successful management of these astronomical expeditions was dependent on an unbroken line of communication. ${ }^{41}$ But Arequipa was much more remote, in terms of communication, than Colorado or California, making William much harder to manage. Worse still for Edward, whereas he could only rarely resort to the costly cablegram, the international press could use it liberally. William, well aware of the newsworthy nature of his visual work on Mars, exploited this discord in telegraphic reach to sidestep the control of his brother. Rather than methodically sending material back to Cambridge for Harvard Observatory to analyze and publish, William used the news media and the telegraph to take his own observations and claims straight to an international audience of millions. Knowing full well that it would take well over a month for Edward to get back a word in reply, William wrote to his increasingly angry brother three weeks before opposition indicating his immediate intentions. "My talents don't lie in the direction of publishing big and complete catalogues. Your talents do. I think I had better do what I am best fitted for. It is better to publish a short article well, and make discoveries, than to publish long articles poorly." $\$ 2$

William's potential discoveries took on momentous proportions even before he had cabled a word back to the United States. With the newspaper press already worked up into a frenzy over what might be seen on Mars, northern observatories, in particular the Lick, suddenly dampened the mood by reporting in early August that viewing conditions in the Northern Hemisphere were poor. Suddenly, South American observations assumed an enhanced significance. George Airy at Greenwich flatly rebuffed an approach from the Associated Press (AP) by reminding them that his observatory was too far north, did not have a powerful enough telescope, and suffered under "thick" weather. "The best results," he stated, "ought to be expected from the observatory of Professor Pickering, of Harvard College, who is taking observations from a point at the top of the Andes in Peru." ${ }^{33}$

For several days around the opposition, which occurred early in the morning of 4 August, readers were therefore presented with a somewhat mixed and confusing account of events. Before any report from Peru had been received, and with ideological and practical reasons for downplaying the opposition's importance, Edward Holden, Asaph Hall, and Edward Pickering all went out of their way to dampen expectations and limit sensation. Hall, at the Naval Observatory in Washington, told the New York Times that "he did not understand why there should be such general popular interest" in the opposition and that "no special phenomena have been observed and none are expected." Edward Pickering, in an interview with the Herald at Harvard Observatory, stated matter-of-factly that "contrary to general opinion, this opposition is of less interest to astronomers than to the general public.” The Herald, no doubt disappointed by Edward's damp squib, ran the interview under a headline that trumpeted what exciting things might be discovered by his brother in Peru. There was, however, no way of sugarcoating the surly screed that Holden telegrammed to the paper from California:

\footnotetext{
${ }^{40}$ This point was often stressed in pieces the Herald ran that thanked the paper for its assistance in transmitting William's observations: "Appreciation of the Herald's Enterprise," N. Y. Herald, 12 Aug. 1892, p. 6; "Herald Service Appreciated," ibid., 2 Sept. 1892, p. 7; and "Professor Pickering Thanks the Herald," ibid., 9 June 1893, p. 8.

${ }^{41}$ Nisbett Becker, "Professionals on the Peak" (cit. n. 7).

${ }^{42}$ W. Pickering to E. Pickering, 15 July 1892, Papers of William H. Pickering. Edward's stern letter of reply wasn't sent until 7 August, so it would have reached William well after the opposition of Mars was over.

43 "Observations of Mars from Greenwich," Baltimore Sun, 12 Aug. 1892, p. 2. Regarding dim expectations for viewing in the Northern Hemisphere see, e.g., "Mars and His Satellites," ibid., 2 Aug. 1892, p. 1. At U.S. and European latitudes Mars was low in the sky, a point Holden was particularly keen to stress: "Opposition of Mars," San Francisco Chronicle, 4 Aug. 1892, p. 3.
} 
The great interest which is felt on this subject by the public is a remarkable proof of the way in which knowledge is now disseminated by the newspaper press.... When every newspaper has its scientific column ... and when the popular books and articles of Proctor and Flammarion are so ready of access ... the effect ... appears to be that a very great number of highly intelligent persons have a living interest in a very great number of scientific questions. ... There is, however, I think, a bad side to this intimacy, which results from the very uncritical attitude of the public to what is printed, and I have especially remarked this point in relation to the observations of Mars at the present time. The tenor of the telegrams which I have seen so far would seem to indicate that it was expected of astronomers that they should conclusively prove that Mars is inhabited by beings like ourselves. ... It also seems to me that several popular writers are doing far more harm than good in encouraging such baseless hopes. ${ }^{44}$

These doubts proved, initially, to be prescient. The first accounts of the opposition to be reported in the United States were from North American observatories, many of which had newspaper reporters outside their door, clamoring for news. But with bad weather and Mars's poor location in the sky having greatly diminished seeing conditions in the Northern Hemisphere, even the Herald had to admit on 5 August that there were "NO GREAT DISCOVERIES IN REGARDS TO MARs." There remained, however, one ray of optimism amidst all the gloom. "Harvard's Annex in [Peru]," explained a deck below the headline, "Expected to Furnish Much Valuable Data about the Neighbouring World." ${ }^{\prime 5}$ All they had to do was wait for it.

The Herald need not fret, however, that it might be beaten to the news. Because the paper had exclusive access to Scrymser's newly constructed telegraphic link between South and North America, it had a monopoly on cabled news from Arequipa. With close working relations already established between the paper and William Pickering, in early August the Herald's correspondents in both Lima, Peru, and Valparaíso, Chile, telegraphed the astronomer asking for two hundred words giving a full account of his observations. William, by now on bad terms with his brother-and always happy to secure publicity for himself-happily obliged without first contacting Cambridge.

Harvard Observatory's archive allows us to trace the material movement of William's observations from the telescope to a global readership in a matter of days. First William wrote out a 211 -word message, by hand, summarizing his observational notes in the typical curt diction of the telegram. (See Figure 3.) He then sent this message over the local Peruvian network from Arequipa to Lima, after a short delay sorting out prepayment, on 8 August. ${ }^{46}$ William's dispatch was then forwarded by the Herald's correspondent in Lima through Scrymser's network to the New York office, where it fell to the paper's journalists to interpret the short, unpunctuated message and transform it into a complete article. This appeared in both American and European editions of the paper on 10 August, as well as in a host of syndicated partners, including the Boston Daily Globe, the Chicago Tribune, the St. Louis Post-Dispatch, and the San

\footnotetext{
44 “Watching All Over the Globe," N. Y. Times, 5 Aug. 1892, p. 1 (see also "No Canals on the Planet: So Say Observers at the Naval and Lick Observatories," Washington Post, 4 Aug. 1892, p. 2); "Observations in Peru: Harvard's South American Annex Expects to Do Good Work," N. Y. Herald, 3 Aug. 1892, p. 3; and "There Is a Bad Side: Professor Holden Points Out the Danger of Expecting Too Much," ibid., p. 3.

45 “No Great Discoveries in Regards to Mars," N. Y. Herald, 5 Aug. 1892, p. 4.

${ }^{46}$ William Pickering telegram to Herald office, Lima, [8 Aug. 1892]; W. Pickering to Baker, 8 Aug. 1892; and W. Pickering to Henry Wolfe, 8 Aug. 1892: Records of Director Edward C. Pickering. See also W. Pickering to C. Pickering, 7 Aug. 1892, Papers of William H. Pickering.
} 


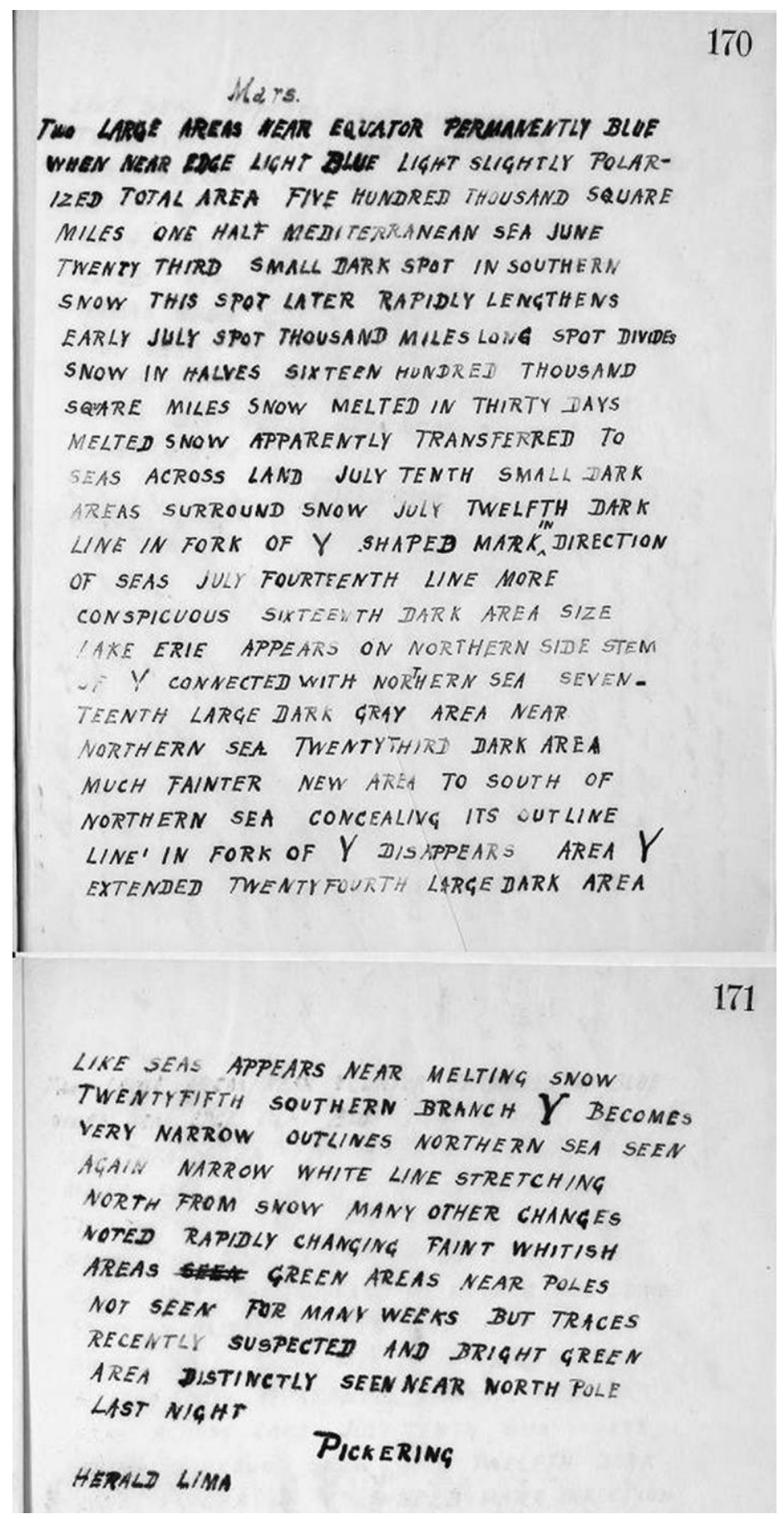

Figure 3. William Pickering's first telegram to the New York Herald, sent to the Lima office on 8 Aug. 1892. From the Arequipa Observatory's outgoing mail copybook. Courtesy of the Harvard University Archives. 
Francisco Chronicle, all of which were able to secure local exclusives by publishing the news on the same day as the Herald, a day ahead of the inevitable reprints in nonsyndicated rivals. ${ }^{47}$

William's account sparked just the sensation that the Herald had doubtless been hoping for. While Northern Hemisphere astronomers had been reticent to claim any new discoveries or draw any new conclusions about what they saw, William's account read like the chronicle of an explorer who had returned from an unknown land, teeming with new revelations. William's frenetic, clipped telegram ("EARLY JULY SPOT THOUSAND MILES LONG SPOT DIVIDES SNOW IN HALVES ...") was converted by the Herald's journalists into a breezy and exciting narrative, presented in the first person: "In my observations of Mars I have seen two large areas near the equator which are permanently blue. ... Sixteen hundred thousand square miles of snow have melted within the last thirty days. The melted snow has apparently been transferred to the sea, across land." In a separate commentary piece, the Herald focused on the remarkable degree of change that William was describing, the scale of which dwarfed any analogous transformations on Earth and "perhaps throw $[s]$ more light upon the physical condition of a neighboring planet than have ever before been obtained." 48

Because these observations were new discoveries, describing details and features never before reported, the Herald and its syndicated partners presented their articles as a discrete news event: the scoop. William's account stood out precisely because of its unique observations, and the immediate effect was to reignite debates over "seeing" and the work of mountain observatories. Seen in terms of isolated sites with privileged views of Mars, William's report was interpreted by some newspapers as a "victory" for Harvard over Northern Hemisphere observatories, particularly the Lick. The debate that ensued was, simultaneously, about the technological priority of those few, privileged sites; the observational competence of the small number of astronomers who worked at them; and the journalistic propriety of sensation-seeking editors. The consequence of these entangled arguments was the emergence of a new narrative about Mars, centered on a single feature of the planet.

\section{TELEGRAMS, INTERPRETATION, AND THE EMERGENCE OF THE “CANAL” NARRATIVE}

Before William Pickering's telegram arrived it had looked to some like the Herald might be dangerously overhyping its Mars coverage. Reliance on Flammarion's exciting cables from France, in particular, had exposed the paper to embarrassment, given that nothing new of note had so far been seen. When Holden began working the press hard in early August with his message of caution and skepticism, certain rivals of the Herald jumped at the opportunity to use these assertions to mock their sensation-mongering rival. Holden had explicitly rejected the exploration trope, stating that "the case is not as though astronomers were pushing out on an unknown ocean expecting to find an unknown continent or a passage to India beyond the sea. In such a case the mere announcement of the discovery would be all that was needed and expected. The actual circumstances are very different. It is as if someone had undertaken to make a new survey of the State of Arkansas, for example." ${ }^{49}$

\footnotetext{
47 "Observations of Mars in South America," N. Y. Herald, 10 Aug. 1892, p. 3; "Large Areas of Blue: Seas Seen One-Half Size of Mediterranean," Boston Daily Globe, 10 Aug. 1892, p. 4; "Many Changes Noted in Fiery Mars," Chicago Tribune, 10 Aug. 1892, p. 1; "Studies of Mars," St. Louis Post-Dispatch, 10 Aug. 1892, p. 2; and "As Viewed from Peru: Phenomena Seen in the Red Planet," San Francisco Chronicle, 10 Aug. 1892, p. 1.

48 “Observations of Mars in South America”; and "Melting of Mars' Snow-Cap," N. Y. Herald, 10 Aug. 1892, p. 6.

49 “Making New Map: Why Astronomers Watch Planet Mars," Boston Daily, 4 Aug. 1892, p. 4.
} 
On 6 August the Washington Post, in a tongue-in-cheek editorial, dubbed the Lick's director "Heartless Holden," jokingly chastising him for "crushing" the claims of "journalistic astronomers" who were happily "giving to the world the fruits of their unleavened ignorance." A day later the New York Times went even harder at Flammarion and the Herald, publishing a spoof report on "The Folks on Mars" that equated the French astronomer with a psychic medium in Denver and the "weather prophet" E. Stone Wiggins. "Old-fogy astronomers . . . are always averse to telling what they know quickly enough to make the information available for timely and lively articles in sensational newspapers, but happily there are other scientists always willing to tell a great deal more than they know, if necessary, in order to entertain the public." ${ }^{50}$ This pointed criticism came crashing down three days later, when the Herald scooped its rivals with the freshest, most impressive news from Mars yet to appear.

With William Pickering's account as the new standard for Martian astronomy, the narrative was quickly reversed. Holden and his conservative colleagues were now singled out as failures who had flunked the astronomical challenge of the decade because of their overly cautious approach. On 11 August the San Francisco Chronicle reprinted at length a particularly cutting reproach from the Brooklyn Times that accused Holden of being an incompetent observer who had secured his position through backroom political influence and had then used it to charge "\$30 a column" for the privilege of printing accounts verified by the "Holden trade-mark." His greatest crime, however, was that he had almost succeeded in ruining the astronomical news event of the season. "When the eyes of the United States were fixed on Mars, lo, there stood between the star and the people the form of Holden. He notified the expectant public, as with the voice of an oracle, that there was not much to see, anyhow." 51

Although astronomers at the Lick received William Pickering's news from Mars "with a kind of amazement," they were very clearly backed into a corner. ${ }^{52}$ Either Holden and his staff were not competent enough to see what William saw or their site was inferior to Harvard's outstation. For the press, the notion that William's observations might be in error did not enter the conversation. The credibility of California's preeminence in the new mountain astronomy thus hinged on both what the Lick could do next and what the newspapers would say next. Even papers that were natural enemies of the Herald, such as the New York Times, and that had lauded the preeminence of the Lick before 10 August started to give preeminence to William Pickering's observations afterward..$^{53}$ On 18 August Holden moved to preempt further debate, sending a telegram to the Herald syndicate's principal rival, the Associated Press:

Up to the middle of August many of the canals of Mars discovered in 1877 by Prof. Schiaparelli were mapped here this year, but no one of them was seen to be double. On the night of August 17, Profs. Schaeberle, Campbell and Hussey made three entirely Independent drawings, each of which shows the canal marked "Ganges" on Schiaparelli's map to be distinctly double. Thus the Lick Observatory has the pleasure of confirming the discovery of Prof. Schiaparelli in 1892, as it already had done by its observation of $1890 . .^{54}$

\footnotetext{
50 “Heartless Prof. Holden," Washington Post, 6 Aug. 1892, p. 4; and “The Folks on Mars," N. Y. Times, 7 Aug. 1892 , p. 4.

51 "Hot Shot for Holden: A Brooklyn Paper's Sharp Criticism," San Francisco Chronicle, 11 Aug. 1892, p. 1.

${ }^{52}$ Edward Holden, "The Lowell Observatory in Arizona," Pub. Astron. Soc. Pacific, 1894, 6:160-169, on p. 166.

${ }^{53}$ E.g., the New York Times London correspondent's pro-Lick cable of 7 August can be contrasted with "Color Changes upon Mars: What Prof. Pickering Has Observed While in Peru," N. Y. Times, 30 Aug. 1892, p. 8.

54 “At Lick Observatory: Mapping the Canals of Mars," Los Angeles Times, 19 Aug. 1892, p. 2. Telegraphically networked syndication arrangements ensured that all Associated Press and Herald pieces during the "great Mars boom" appeared simultaneously in most major cities in the United States and Europe.
} 
This was a remarkable about-face from an astronomer who had previously complained loudly and often about the unsuitability of newspapers for the announcement of astronomical findings. It was also a subtle massaging of the facts, phrased in such a way as to sound like the Lick had already, in 1890, confirmed Schiaparelli's double canals. In fact Holden had, until this telegram, persistently insisted that though astronomers at the Lick saw Schiaparelli's canals, they had only rarely seen them double, and when they had such observations were never unanimous amongst his staff. 55 The shift to confirming Schiaparelli's doubling - or "gemination," as he called it - was a significant one. Not only did it thrust the canals, as a feature, even further into the limelight; it did so by corroborating their apparent periodical doubling into parallel lines - a seemingly bizarre phenomenon that greatly enhanced the possibility that they might be artificial. Holden, of course, intended that his confirmation be taken as nothing more than an observational one, but, as might have been expected, the immediate press response was to speculate over what the double canals might be. ${ }^{56}$

This shifted the narrative of the ongoing Martian opposition in an important way. Whereas William Pickering's telegram from Arequipa had depicted Mars as a complicated, varied, and continually changing planet, Holden's telegram now focused attention on one, apparently persistent, feature. As the Herald wrote in response to the Lick's report: "The chief thing in the telescopic study of Mars now is an explanation of the 'canals' and of their gemination. It is hoped by many that while Mars is in a favourable position some observer will be able to clear up this mystery." No doubt the Herald expected that observer to be William Pickering; satisfyingly, he obliged a week later-of course unknowingly, being himself without newspaper access-sending a second telegram from Arequipa that, unlike the first, confirmed that "many of Schiaparelli's canals have been seen single." 57 The fact that this simultaneously accorded with Holden's own claims (that Schiaparelli's canals were seen) and contradicted them (they were seen single, not double) only helped compound what was already a deeply ambiguous and confused discussion.

Yet for the press it was just this mystery that made the canals such a compelling and salable news story. In the slow news days of the summer, papers across America and Europe readily seized on the opportunity to spin out numerous articles and editorial notes about these strange dark lines. Much more than any reports of melting snow or elaborate mountain ranges ever could, the conundrum of the canals neatly fit the characteristics that newspapers looked for in a story: on the one hand, they were a single, recognizable feature that could be returned to again and again; and on the other hand, their very ambiguity in appearance and meaning allowed for a steady stream of exciting, varied, and speculative articles. In the weeks following William's second telegram, the newspapers buzzed with news of his "important data as to the curious straits or canals on [Mars's] surface." A conjunction of cycles-astronomical and news - created a sensation that did not settle down until the serious business of the coming

\footnotetext{
${ }^{55}$ E.g., Holden, "Notes on the Opposition of Mars, 1890" (cit. n. 30); "A Square Look at Mars: The Lick Telescope Dispels Many Erroneous Theories," N. Y. Times, 1 Aug. 1892, p. 5; and "No Canals on the Planet" (cit. n. 44).

${ }^{56}$ E.g., Dr. Paul Gibier, "Possible Uses of Mars' Canals," N. Y. Herald, 21 Aug. 1892, p. 22, which speculated that the canals might be an artificial irrigation network or highways. This report was widely reprinted and excerpted, first through syndication and then through the usual practice of flagrant copying or rewording by nonsyndicated papers in subsequent days and weeks. Schiaparelli himself, as always, remained ambiguous about the implications of the doubling that he saw: "Life on Mars: Prof. Schiaparelli Says "Tis a Theory," Boston Daily Globe, 5 Aug. 1892, p. 1.

57 “The Double 'Canals' of Mars," N. Y. Herald, 20 Aug. 1892, p. 6; and "Melting Snow in Mars: Professor Pickering, at Arequipa, Peru, Makes Many Interesting Discoveries: Schiaparelli’s Canals Seen,” ibid., l Sept. 1892, p. 7. William wrote Holden on 1 September that "we are so out of the world that we haven't heard a word yet of what has been done on Mars by any other Observatory": Records of Director Edward C. Pickering.
} 
presidential election took back the press agenda in the autumn. By then, the Martian canals were already a cultural phenomenon - and one that even politics couldn't entirely escape. "If Mr. [Grover] Cleveland wishes to please the Republicans," wrote the Herald on 15 September, "he will confine his letter to speculations concerning the canals of Mars and let American tin alone." The Democrats, another paper proclaimed, had "no more to do with [Federal] money coming to [New York] State than they had with digging the canals of Mars."

The bitter irony for Holden and William Pickering is that neither of them had intended that his reports be interpreted in this way. In their competitive pursuit of press exposure, they had both lost control of the narrative. Holden, ever the conservative observer, had always remained reluctant to speculate in any way about the nature of Schiaparelli's dark, linear markings. Yet merely by confirming their existence he was drawn into very public debates that he had no desire to be associated with. As he later noted in his end-of-opposition report for Astronomy and Astro-Physics, "The present note may serve a useful purpose in correcting certain erroneous statements regarding our work which have been widely circulated and which require correction." William Pickering was clearly much happier to speculate about Mars's geographic features and habitable conditions than Holden was, yet he too had his doubts about the canals, having suggested as early as 1888 that they might actually be vegetation, rather than waterways. His observations at Arequipa in 1892 only served to convince him further that Schiaparelli's depiction of Mars was overly simplistic, and he wrote to his brother on 7 July that "I don't take much stock in Schiaparelli's canals on Mars. There are some coarse ones there undoubtedly, which were seen by others before him. There is also some extremely fine detail, which I never saw before, but I don't think it takes the form of canals, at least not as drawn by Schiaparelli." 59

William's observations, summarized in his telegrams to the Herald, were clearly intended to sweep away what he saw as a limited and flawed description and provide instead a completely fresh view of the planet, with the "canals" incorporated into a much more varied, complex, and dynamic representation. But by mentioning them at all, William played into a narrative that the newspapers had already begun to form, in which the canals were the central feature of an ambiguously living world.

The genre with which Holden and William Pickering engaged very much exacerbated this problem of interpretation. Newspapers were ideal because of their speed and their reach, but these features came at the expense of detail. Relying exclusively on the telegraphic network to move international astronomical news meant that the opposition of 1892 played out entirely without the exchange of drawings, photographs, or maps. As Holden had always stressed, it was the exchange and accumulation of these images of Mars that allowed astronomers cautiously to build up an accurate picture of what the planet looked like. ${ }^{60}$

Working exclusively with words left a great deal more to interpretation, a problem further exacerbated by the impact that the telegraph itself had on language. The financial imperative for brevity produced a clipped telegraphic vernacular that was stripped of detail and separated the observer from the writer. Required as both a transporter and a mediator, newspapers necessarily interpreted telegrams to make stories. ${ }^{61}$ Detailed descriptions of intricate planetary detail and complex topographical changes could neither be conveyed using the telegraph nor were

\footnotetext{
58 "Peeps at a Planet," Auburn (NY) Bulletin, 19 Sept. 1892, p. 6; "Summary of the News," N. Y. Herald, 15 Sept. 1892 , p. 8; and "Does Reduction Reduce?” Havana (NY) Journal, 15 Oct. 1892, p. 4.

${ }^{59}$ Edward Holden, "Note on the Mount Hamilton Observations of Mars, June-August, 1892," Astronomy and Astro-Physics, 1892, 11:663-668; and W. Pickering to E. Pickering, 7 July 1892, Papers of William H. Pickering.

${ }^{60}$ Holden often made this point to the press; see, e.g., "Opposition of Mars" (cit. n. 43).

${ }^{61}$ Carey, Communication as Culture (cit. n. 3), pp. 162-163.
} 
desired by newspapers looking for salable copy. By the time William Pickering could publish his own drawings of Mars in a special issue of Astronomy and Astro-Physics, the "boom" was already winding down, and his visual representation of dramatic change over time did not reach a public consciousness that had already consumed the newspapers' image of Mars as a more or less static, canal-covered planet. (See Figure 4.)

The ambiguities inherent to such newspaper interpretations were also amplified by the ambiguity of the word "canal" itself. What astronomers saw were dark, straight lines, necessarily at least twenty miles across and often thousands of miles long. As Schiaparelli himself noted, both brevity and conventional analogical terminology lead him, for simplicity and clarity's sake, to dub these features "canali." Ironically, William Pickering was among the first astronomers to note the possible danger of providing such puzzling features with such a concrete name, writing in 1890 that "it seems to me most unfortunate that the name of canals bas been attached to these finer markings upon the planet, for there has not been the slightest evidence brought forward in support of the supposition that they are filled with water." ${ }^{2}$ Even if what they were seeing was water, as many astronomers believed, the name still provided a dangerous terrestrial analogy that was ripe for misinterpretation. ${ }^{63}$ It is telling, therefore, that at precisely the moment that this risk of misinterpretation became most pressing, thanks to the press furor over Holden's and William Pickering's observations, the argument emerged that the appellation of "canal" derived from an unfortunate mistranslation. Norman Lockyer, in an angry 8 September note in his own journal, posited that the translation of Schiaparelli's Italian might be the root cause of the sudden and unnecessary sensation. "These streaks he called canali, which in Italian, as canalis in Latin, means either a channel, a canal, or a pipe. Unfortunately, however, whenever it has been translated into English the word canal has been used, which of course with us suggests human labour. We have already seen what this has led to." Mistranslation, therefore, which has subsequently been posited by almost every historical account of the "canal controversy" as its root cause, must rather be understood as a partisan explanation deployed by certain actors during the debate itself. ${ }^{64}$ The complex rendition of images as words, via the telegraph and across mass media, generated for some a crisis of translation, in which the meaning of observations risked being lost in the message. Mistranslation became one plausible way to explain away this problem of linguistic ambiguity. ${ }^{65}$

Newspapers, for their part, were happy to revel in these ambiguities. They need not worry if the word "canal" might suggest artificiality, and they actively relished the terrestrial analogy

\footnotetext{
${ }^{62}$ Markley, Dying Planet (cit. n. 6), p. 55 (Schiaparelli's explanation of his term); and Pickering, "Visual Observations of the Surface of Mars" (cit. n. 27), p. 369

${ }^{63}$ Holden, e.g., argued that if one analyzed drawings of Mars alone, ignoring written descriptions, it became evident that "there are enormous difficulties in the way of completely explaining the recorded phenomena by terrestrial analogies unless we also introduce serious modifications": Holden, "Note on the Mount Hamilton Observations of Mars" (cit. n. 59), p. 668. On Mars and terrestrial analogy see Markley, Dying Planet, pp. 31-114; and Lane, Geographies of Mars (cit. n. 6), pp. 141-185.

${ }^{64}$ Lockyer, "Opposition of Mars" (cit. n. 38), p. 447. Recourse to the mistranslation claim is nearly ubiquitous in secondary literature on the canal controversy. I have found at least twenty-five pieces that present it as the explanation for the controversy; none of them mention its historical origins in the debate itself. Two recent works that express admirable caution with respect to the claim are Markley, Dying Planet, p. 55; and Lane, Geographies of Mars, the second chapter of which persuasively posits a visual rather than textual explanation for the interpretation of Schiaparelli's canals as artificial.

${ }^{65}$ Lockyer's argument was soon taken up by other critics of claims about the nature and extent of Mars's canal network, most notably Simon Newcomb and Alfred Russel Wallace. The former made the claim in his articles on Mars for both the tenth and eleventh editions of the Encyclopaedia Britannica, as well as in various popular books and articles. Wallace made the claim in both The Wonderful Century: The Age of New Ideas in Science and Invention (London: Swan Sonnenschein, 1903), p. 239; and Is Mars Habitable? A Critical Examination of Percival Lowell's Book "Mars and Its Canals," with an Alternative Explanation (London: Macmillan, 1907), p. 3.
} 


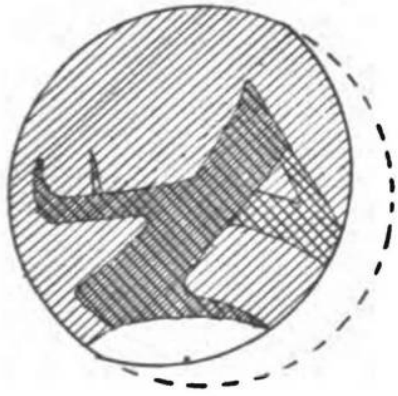

Fig. 1.

May $9,21^{\mathrm{h}} 05^{\mathrm{m}}$

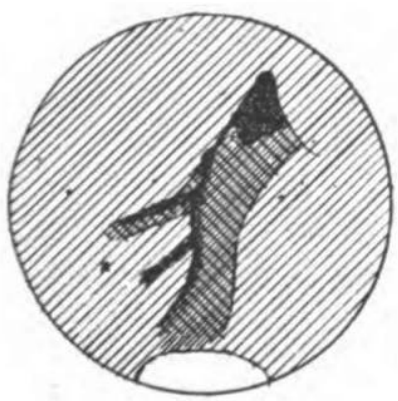

Fig. 3.

July $16,17^{\text {h }} 45^{\text {m }}$

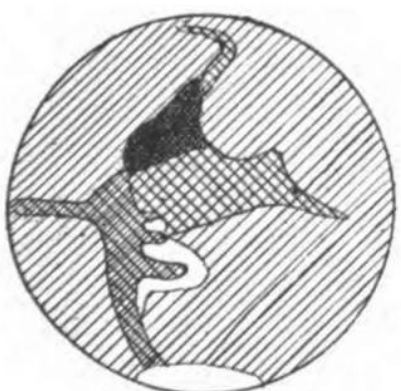

Fig. 5.

July $23,17^{\text {h }} 30^{\text {m }}$

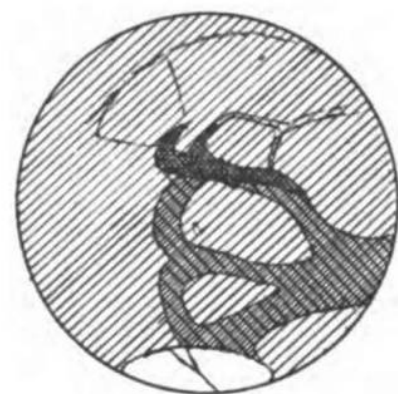

Fig. 2.

July $14,16^{\text {h }} 50^{m}$

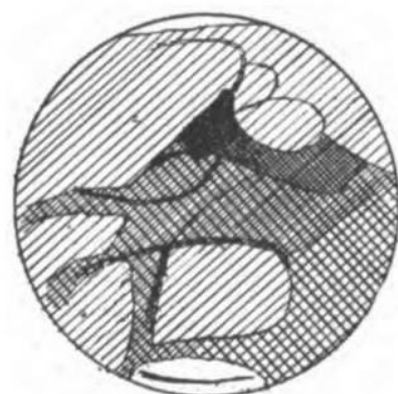

FIG. 4.

July $17,15^{\text {h }} 50^{\text {m }}$

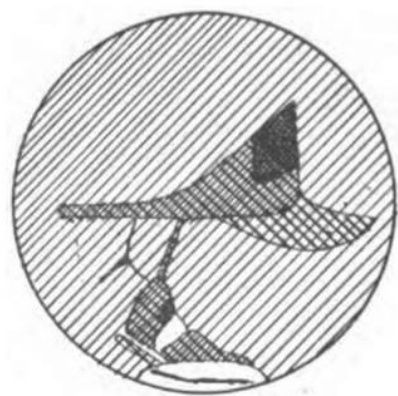

Fig. 6.

July $25,20^{\text {h }} 40^{\mathrm{m}}$

Figure 4. Drawings of Mars by William Pickering, presented in series, showing complex changes in the planet's physical appearance during the 1892 opposition. Unlike his telegraphic reports of the canals, such images did not appear until well after the "great Mars boom" was over and even then reached only a small, specialist audience. From William Pickering, "Mars," Astronomy and AstroPhysics, 1892, 11:668-675, Plate 30. 
that it implied. By taking what Holden and William Pickering had written and interpreting it for their own ends, they took a single feature, described by a single, potentially problematic word, and placed it at the center of the 1892 opposition. Newspapers, more than any other medium, played an active role in transmitting the events of 1892 as they happened, shaping the public perception of Mars as a "canal"-covered planet. This canal narrative would be the enduring legacy of the "great Mars boom."

\section{CONCLUSION}

At the heart of "event astronomy" was a powerful alliance between internationally networked newspapers and new, remote sites of astrophysical work. A close analysis of debates over the physical constitution of Mars during the 1892 opposition suggests that two intertwined problems loomed large in this new astronomical order. On the one hand, astronomers had to grapple with the question of how to present their observations in the public sphere. How should facts or discoveries made at a single, specific site be rhetorically shaped into messages that could travel, nearly instantaneously, across the globe to audiences that numbered in the millions and ranged from expert colleagues to readers of the penny press? Edward Pickering's response to his brother's global sensation cut right to the heart of the matter:

[Your] telegram to the N. Y. Herald has given you a colossal newspaper reputation. A flood of cuttings have appeared, forty nine coming this morning. In my own case I should have restricted myself more distinctly to the facts in this as in other cases. You would have rendered yourself less liable to criticism if you had stated that your interpretations were probable instead of implying that they were certain. A reexamination of your telegram shows that it is more guarded than some newspaper versions of it. ${ }^{66}$

The necessary flip side of this division over transmission practices, therefore, was that newspaper editors and journalists had to grapple with the question of how to present competing claims about Mars, faced with contested claims to authority and contrasting abilities to generate successful copy. Despite the obvious appeal of the canal sensation, at least some journalists took time to worry about their new position as the discipline's principal gatekeepers of information exchange. Milicent Shinn, a personal friend of Edward Holden and a major player in California journalism, worried that the disjuncture between Holden's "curt and cautious dispatches" and William's "interesting ... speculation" raised serious issues of propriety and expertise for her profession. "Newspapers ought not to lend themselves to such crude notions as that the use of great telescopes is to discover people and houses on the moon, canals and electric lights on Mars.... The editors that know this are the ones that should be entrusted with the editorials on scientific matters." ${ }^{\prime 7}$ Astronomy and journalism's relationship was a symbiotic one, but it was also a problematic one.

I have argued here that a close analysis of this problematic relationship demonstrates the ways in which transmission technologies shaped the construction of new knowledge about Mars. This influence is evident in two complementary ways. First, within the tight time frame of the immediate episode analyzed here - the "boom" of August and September 1892 - we see how the linguistic limits, communication speed, and geographical scope of submarine telegraphy shaped and bounded what could be said about, and therefore what could be known about, Mars. The result was a particular focus on one persistent feature-the planet's canals-despite

\footnotetext{
${ }^{66}$ E. Pickering to W. Pickering, 24 Aug. 1892, quoted in Jones and Boyd, Harvard College Observatory, p. 307.

67 “Etc.," Overland Monthly, 1892, 20:328.
} 
the intentions of William Pickering himself. This focus, therefore, was not merely a "secondorder" effect of public reception. Precisely because astronomers themselves, on all sides of the debate, came to rely so completely on newspapers like the Herald and its AP rivals to communicate their observations and arguments quickly and globally, telegraphic news became a constitutive part of astronomical work on Mars. Nowhere is this effect clearer or more striking than in the response of Edward Holden, who despite decrying the rise of newspaper astronomy before the "boom" responded to William's sensational reports with his own counter-report, telegraphed to the AP, announcing the Lick's observations of doubled canals. The 1892 nexus of a very few remote giant telescopes, globally networked newspapers, and rival astronomers keen to secure status, priority, and reputation combined to construct the canals on Mars as the central feature of an ambiguously living planet.

Second, then, we must also attend to the long-term effects that this construction of a canal focus had on debates that continued well into the twentieth century. Though a detailed account of these effects is beyond the scope of this essay, it is important to note how influential the "great Mars boom" was for subsequent astronomical work on the planet's physical geography and habitability. After 1892, astronomers of markedly differing views and skill sets configured their Martian work in terms of what the canals might be, while continuing to propagate this work in an extremely wide range of media types, to a huge and diverse audience receptive to, as Agnes Clerke put it, "news from Mars." Thus it was that François Terby could celebrate, in the wake of the "boom," the decisive defeat of "Schiaparellophobomania" among astronomers who had been on the fence about the existence of Schiaparelli's enigmatic features before 1892. ${ }^{68}$

No one, of course, tapped into this post-"boom" focus on the Martian canals with more alacrity or success than the person who would come to dominate the "Martian canal controversy" for the next two decades: Percival Lowell. Lowell, my account makes clear, was a late arrival to these debates, and his success must be understood in light of the events of 1892. From the very outset of his work on Mars in 1894, Lowell explicitly linked his self-funded "investigation into the condition of life in other worlds" to a focused study of one singular entity, "the canals of Mars," which he took, at the outset, to be "probably ... the result of the work of some sort of intelligent beings." Crucially, Lowell utilized in this work two resources inaugurated during the "boom." An accomplished author and public speaker, he shaped his canal work from the start to fit the preexisting news infrastructure and market established by Pickering's reports from Arequipa. (The Herald would become an ally and collaborator.) $)^{69}$ And, quite directly, Lowell attached his project to the epicenter of the "boom," hiring William Pickering away from Harvard to establish his observatory in Flagstaff, Arizona. To skeptical onlookers like Edward Holden, the threat was quite clear. In an editorial broadside against Lowell's project, Holden accused the Boston newcomer of failing to separate carefully "conjectures from acquired facts." Such misleading and unfortunate statements were, he warned, all the more harmful because they were "well written" and "likely to be widely copied in other periodicals." This was not a new threat. Holden explicitly framed his critique of Lowell's project in terms of the "great Mars boom." Quoting at length from William Pickering's 1892 telegrams, as reported in the Herald, Holden returned his audience to the "boom" in order to diagnose the threat posed by Lowell's event astronomy before work in Flagstaff had even begun. In rereading

\footnotetext{
${ }^{68}$ Over a hundred astronomical works published in the wake of the 1892 opposition are analyzed in Crowe, Extraterrestrial Life Debate (cit. n. 1), pp. 496-502; for "Schiaparellophobomania" see ibid., p. 499.

${ }^{69}$ Quoted in Holden, "Lowell Observatory in Arizona" (cit. n. 52), pp. 161-162. The literature on Lowell is extensive. See esp. the works cited in notes 1 and 6, above; and David Strauss, Percival Lowell: The Culture and Science of a Boston Brahmin (Cambridge, Mass.: Harvard Univ. Press, 2001).
} 
William's Herald reports "it is obvious, at first glance," Holden concluded, "that the superstructure of announcement is too elaborate for the base of observation." ${ }^{70}$ Martian canals as a single, defining feature of the red planet were one profound consequence of this entanglement of communication and observation. How the rapidly professionalizing discipline of astrophysics should organize and police its working practices, including norms of information exchange and media engagement, was another-and one that, like the canals themselves, would take decades to resolve.

\footnotetext{
${ }^{70}$ Holden, "Lowell Observatory in Arizona," pp. 160-166. On William Pickering's move to Flagstaff see David Strauss, "Percival Lowell, W. H. Pickering, and the Founding of the Lowell Observatory," Annals of Science, 1994, 51:37-58.
} 